\title{
Observed interannual oscillations of planetary wave forcing in the Northern Hemisphere winter
}

\author{
Wen Chen \\ LASG, Institute of Atmospheric Physics, Chinese Academy of Sciences, Beijing, China
}

Hans-F. Graf

Max-Planck-Institute for Meteorology, Hamburg, Germany

Masaaki Takahashi

Center for Climate System Research, University of Tokyo, Tokyo, Japan

Received 6 August 2002; revised 5 September 2002; accepted 24 September 2002; published 29 November 2002.

[1] Using NCEP-NCAR reanalysis data from 1958 to 1998, two interannual oscillations in the eddy forcing due to planetary waves (wavenumbers 1-3) are found in the Northern Hemisphere winter, called as the stratospheric interannual oscillation (SIO) and the tropospheric interannual oscillation (TIO). The temporal evolutions are different between the SIO and the TIO, suggesting different dynamic mechanisms. The planetary waves tend to be bent equatorward in the troposphere during a positive TIO phase, and in the mid- and upper stratosphere during a positive SIO phase. The result also suggests that upward propagation of planetary waves into the polar waveguide across the tropopause is closely associated with the TIO. Further regression and correlation analyses suggest that the TIO is closely linked to the Northern Annular Mode (NAM), whereas the SIO is closely associated with the El Niño/ Southern Oscillation (ENSO). INDEX TERMS: 3319 Meteorology and Atmospheric Dynamics: General circulation; 3384 Waves and tides; 3362 Stratosphere/troposphere interactions; 3334 Middle atmosphere dynamics (0341, 0342); 1620 Global Change: Climate dynamics (3309). Citation: Chen, W., Hans-F. G., and Masaaki T., Observed interannual oscillations of planetary wave forcing in the Northern Hemisphere winter, Geophys. Res. Lett., 29(22), 2073, doi:10.1029/2002GL016062, 2002.

\section{Introduction}

[2] There is an increasing body of evidence that a dipole pattern in the midlatitude zonal-mean zonal wind $(\overline{\mathrm{u}})$ is an important mode of interannual variability in the Northern Hemisphere winter [Dunkerton and Baldwin, 1991; Thompson and Wallace, 2000]. Northern Hemisphere $\overline{\mathrm{u}}$ fluctuations are generally accompanied by large-amplitude stationary waves. DeWeaver and Nigam [2000] indicated a cooperative dynamical relationship between $\overline{\mathrm{u}}$ and stationary wave anomalies, in which each is both a source of and a response to the other. Limpasuvan and Hartmann [1999] showed that variations of the Northern Annular Mode (NAM), which was referred to as a nearly zonally symmetric, North-South movement of momentum across the midlatitudes, are forced by eddy fluxes mainly of

Copyright 2002 by the American Geophysical Union. 0094-8276/02/2002GL016062 stationary waves in the free troposphere of the Northern Hemisphere. Planetary waves are forced in the troposphere by orography and patterns of diabatic heating arising from the distribution of land and sea [Andrews et al., 1987]. During winter the planetary wave propagation from the troposphere to the stratosphere and associated meridional heat fluxes can be altered by the zonal-mean flow structure [e.g., Chen and Huang, 1999]. However, there are only few analyses of the variations of planetary wave activity with respect to climate variability. Accordingly, interannual variations of eddy forcing due to stationary planetary waves both in the troposphere and in the stratosphere are investigated in this short article.

\section{Data and Methods}

[3] This study is based on the monthly mean pressure level data of 41 years $(1958-1998)$ from the National Centers for Environmental Prediction-National Center for Atmospheric Research (NCEP-NCAR) reanalysis [Kalnay et al., 1996]. The seasonal means are constructed by averaging December, January and February (DJF) resulting in 40 winter fields.

[4] The Eliassen-Palm flux (EP flux) is used as a diagnostic tool, which is a measure of the wave activity propagation. The EP flux divergence indicates the eddy forcing of the zonal mean flow [Andrews et al., 1987]. By expanding the winter geopotential height field into their zonal Fourier harmonics, the sum of zonal wavenumbers 1 through 3 is used to represent stationary planetary wave activity. The quasigeostrophic version of EP flux in spherical geometry is employed in calculating its divergence due to planetary waves [Edmon et al., 1980]. For regression and correlation studies we consequently used the effective number of degrees of freedom (EDOF) according to Davis [1976] to check the statistical significance.

\section{Results and Discussion}

[5] The 40 winter divergences of EP fluxes due to ultralong planetary waves of zonal wavenumbers 1-3 are computed from the pressure level data. In order to identify the recurrent spatial patterns which may be indicative of standing oscillations in the planetary waves, we calculate the teleconnectivity in the EP flux divergence 


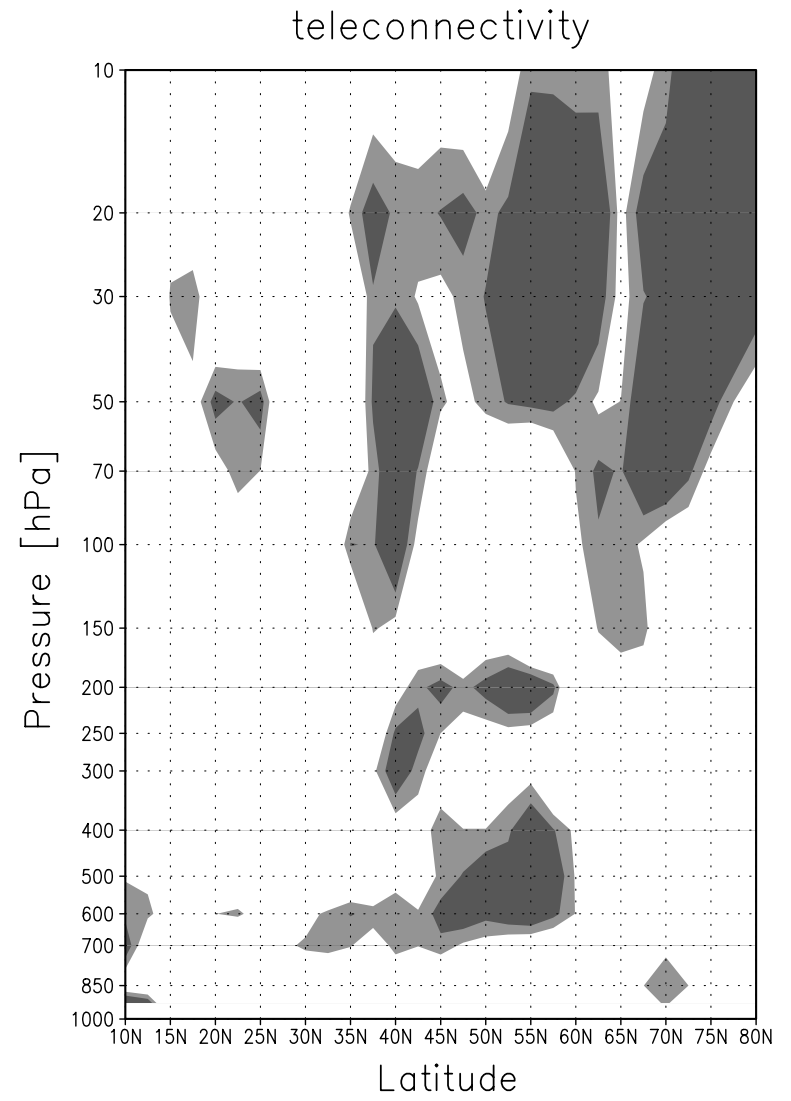

Figure 1. Teleconnectivity of winter EP flux divergences due to planetary waves (wavenumbers $1-3$ ). The light and dark shading areas indicate the absolute correlation coefficients exceeding 0.55 and 0.65 , respectively.

field in the latitude pressure domain as shown in Figure 1. The teleconnectivity represents the maximum anticorrelation obtained at a grid point when that point is correlated with all other grid points [Wallace and Gutzler, 1981]. It's evident that there are large teleconnections both in the stratosphere and in the troposphere. Details of the teleconnection patterns can be elucidated by constructing onepoint correlation maps of EP flux divergences. These can be illustrated in one-point correlation maps with reference points at $30 \mathrm{hPa}, 75^{\circ} \mathrm{N}$ (Figure $2 \mathrm{a}$ ), $30 \mathrm{hPa}, 57.5^{\circ} \mathrm{N}$ (Figure 2b), $500 \mathrm{hPa}, 50^{\circ} \mathrm{N}$ (Figure $2 \mathrm{c}$ ), and $300 \mathrm{hPa}, 40^{\circ} \mathrm{N}$ (Figure 2d).

[6] Figures $2 \mathrm{a}$ and $2 \mathrm{~b}$ with stratospheric reference points have similar patterns with a north-south dipole structure. The large correlation values are found mainly in the stratosphere, whereas only marginal correlation values exist in the troposphere. For the time series at reference points $(30 \mathrm{hPa}$, $\left.75^{\circ} \mathrm{N}\right)$ and $\left(30 \mathrm{hPa}, 57.5^{\circ} \mathrm{N}\right)$ the EDOF is 34 , and the $99 \%$ significance threshold of the correlation coefficient is 0.42 . The cross-correlation value of these two time series is -0.74 , which is by far exceeding the $99 \%$ significance level. Although there are secondary large correlation values around $20^{\circ} \mathrm{N} \sim 25^{\circ} \mathrm{N}$, they will not be considered here for two reasons. First, the use of satellite data since 1979 in the NCEP reanalysis leads to spurious changes in the tropics [Pawson and Fiorino, 1999]. These have a strong effect on the trend and variability analyses mainly around the tropics.
Second, the values of EP flux divergence due to stationary planetary waves in the tropical-subtropical region are small when compared with mid-high latitudes. Figures $2 a-2 b$ represents a stratospheric teleconnection pattern in the EP flux divergence field.

[7] With tropospheric reference points (Figures 2c and 2d) equally strong patterns appear, but with a much more complex structure. The structure here appears to resemble the composite EP flux difference for the zonal wavenumbers 1 to 3 between high and low NAM index [see Figure 3 of Hartmann et al., 2000]. It suggests that basically the process sits in the troposphere, but has impact on the stratosphere. The lower stratospheric high latitude extremes of the troposphere based patterns (Figures $2 \mathrm{c}-2 \mathrm{~d}$ ) are found at latitudes $\left(65^{\circ} \mathrm{N}\right)$ where the stratosphere based patterns have minima (Figures $2 a-2 b$ ). There is also a tendency for the northern part of large correlation values to be suppressed roughly at the $250 \mathrm{hPa}$ level, which is close to the winter tropopause level in higher latitudes. It may be due to the refraction of planetary wave propagation by the upper troposphere polar night jet. Linear wave theory suggests that the upward propagation of planetary waves is refracted into the polar waveguide in the stratosphere by the vertical shear of $\overline{\mathrm{u}}$ near the subpolar tropopause [Chen and Robinson, 1992]. The EDOF is 38 for the time series at reference points $(500 \mathrm{hPa}$, $\left.50^{\circ} \mathrm{N}\right)$ and $\left(300 \mathrm{hPa}, 40^{\circ} \mathrm{N}\right)$, the cross-correlation value of these two time series is -0.66 exceeding the $99 \%$ significance level of -0.40 . Thus, Figures $2 c-2 d$ presents another
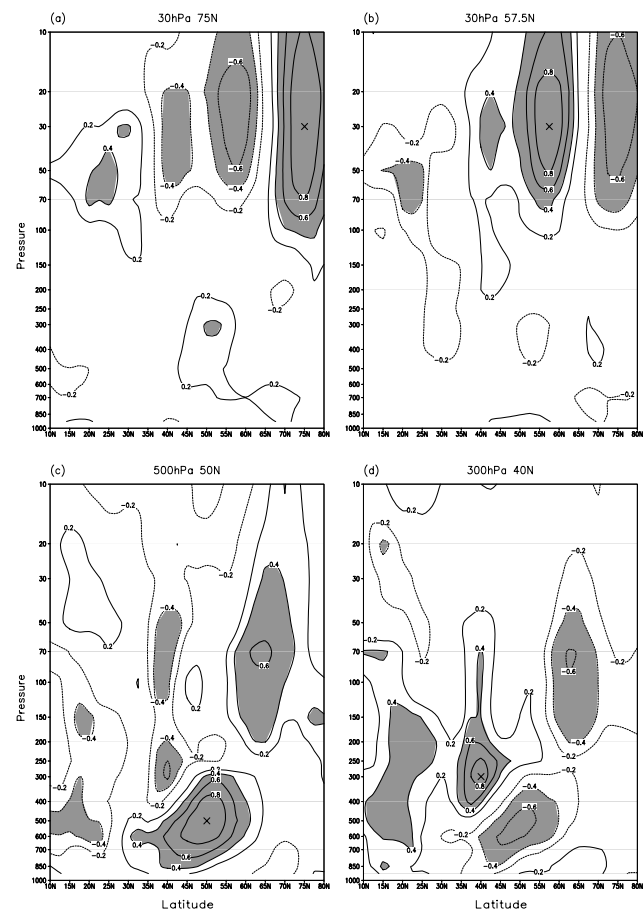

Figure 2. One-point correlation maps of 40 winter EP flux divergences with reference points at $30 \mathrm{hPa}, 75^{\circ} \mathrm{N}$ (a); $30 \mathrm{hPa}, 57.5^{\circ} \mathrm{N}$ (b); $500 \mathrm{hPa}, 50^{\circ} \mathrm{N}$ (c); $300 \mathrm{hPa}, 40^{\circ} \mathrm{N}$ (d). The reference points are marked with " $\times$ ", respectively. The contour interval is 0.2 and the zero contour line has been suppressed. The areas are shaded for absolute values of correlation coefficients $\geq 0.4$. 

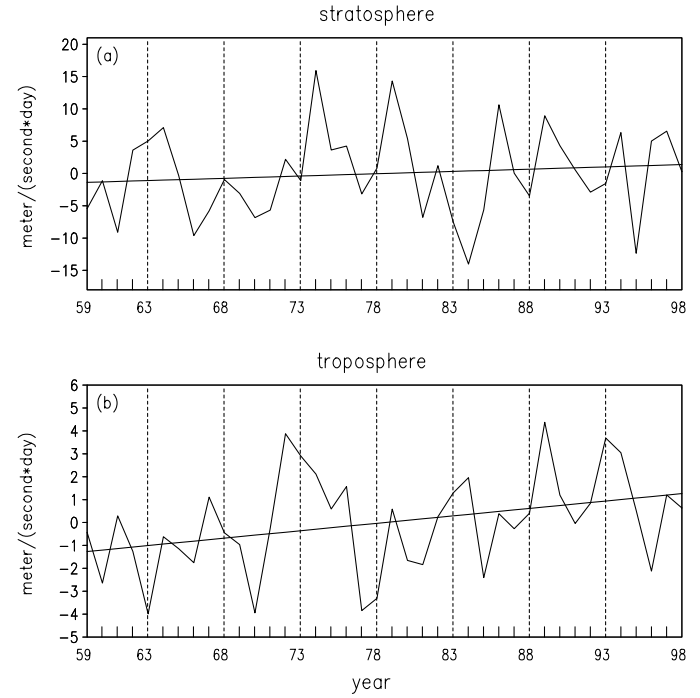

Figure 3. (a) Winter mean (DJF) time series $(1957 / 58 \sim$ 1997/98) of the SIO index together with the linear trend function. (b) Same as in (a) but for the TIO index.

teleconnection pattern for planetary wave forcing mainly in the troposphere.

[8] We define a stratospheric pattern index based on winter anomalies as the difference of EP flux divergence between $75^{\circ} \mathrm{N}$ and $57.5^{\circ} \mathrm{N}$ at $30 \mathrm{hPa}$, and a tropospheric pattern index as that between $50^{\circ} \mathrm{N}$ at $500 \mathrm{hPa}$ and $40^{\circ} \mathrm{N}$ at $300 \mathrm{hPa}$. Thus, a positive pattern index is indicative of anomalously divergence of EP flux in the north and convergence in the south; a negative pattern index indicates anomalies of the opposite sign. Figure 3 shows the time series of the two indices from 1959 to 1998. Here, 1959 indicates the 1958/1959 winter etc.. The tropospheric pattern index has a clear linear trend toward its positive polarity with statistical significance above 99\% (Figure 3b). The stratospheric pattern index is slightly increasing, but not statistically significant (Figure 3a). Both indices have large interannual variabilities. In the following, we shall call these two time variations as the stratospheric interannual oscillation (SIO) and the tropospheric interannual oscillation (TIO) for planetary wave forcing, respectively. The correlation between the two time series in Figure 3 is only 0.2, which is by far not statistically significant, suggesting different causes of the stratospheric and tropospheric oscillations. While the SIO is mostly confined to the stratosphere, the TIO is mostly a tropospheric phenomenon including only the lower part of the stratosphere. Thus, it is reasonable to consider the SIO being physically independent of the TIO.

[9] Linear regression and correlation analyses were carried out in order to assess planetary wave propagation and $\overline{\mathrm{u}}$ anomaly associated with the interannual variations of planetary wave forcing. Before the regression and correlation analyses, both indices were detrended by subtraction of the linear trends. The winter anomalies of EP flux components, its divergence and $\overline{\mathrm{u}}$ were also detrended by subtraction of local linear trends. The EP flux cross sections in Figures $4 a-4 b$ show those anomalies which are associated with SIO and TIO, respectively. With regard to the SIO index, a north-south dipole pattern of EP flux divergence evolves in the high latitudes of the mid- and upper stratosphere (Figure 4a). The planetary waves tend to be bent equatorward and are associated with EP-flux divergence in the north and convergence in the south when SIO is positive. For the TIO index, a dipole of EP flux divergence appears in the midlatitudes of troposphere (Figure $4 \mathrm{~b}$ ). This dipole is associated with anomalous meridional propagation of planetary waves in the troposphere. There is also EP flux divergence along the polar waveguide high up into the stratosphere associated with the positive TIO index. The EP flux anomalies suggest that the upward propagation of wave activity across the tropopause into the polar waveguide in the stratosphere is reduced, and the waves tend to be bent equatorward in the midlatitudes of the lower stratosphere as in the troposphere.

[10] Figure 3b indicates a significant trend of TIO index toward its positive polarity. This means the increasing equatorward propagation in the troposphere and reduced upward propagation into the stratosphere for planetary waves in recent decades. These observational results are consistent with the results from the atmospheric general circulation model [Shindell et al., 1998] and the coupled atmosphere-ocean climate model [Perlwitz et al., 2000] under increased greenhouse gas forcing.

[11] Figure 5 shows the regression (contours) / correlation (shading) map of $\overline{\mathrm{u}}$ upon the detrended SIO index (Figure 5a) and TIO index (Figure 5b). Both oscillations are shown to be associated with the north-south fluctuation of $\overline{\mathrm{u}}$ anomalies across the mid-latitudes, but at different levels and with different correlations. Corresponding to the SIO index, the spatial pattern of $\overline{\mathrm{u}}$ anomalies has a dipole structure in the mid- and upper stratosphere. However, the correlations between the SIO index and $\overline{\mathrm{u}}$ anomalies are modest. A positive SIO index state corresponds to significant weakening westerly anomalies in the subtropics of the mid- and upper stratosphere. Corresponding to the TIO index, the structure of $\overline{\mathrm{u}}$ anomalies is an equivalent barotropic dipole extending from the lower troposphere to the upper stratosphere with reduced westerlies at $35^{\circ} \mathrm{N}$
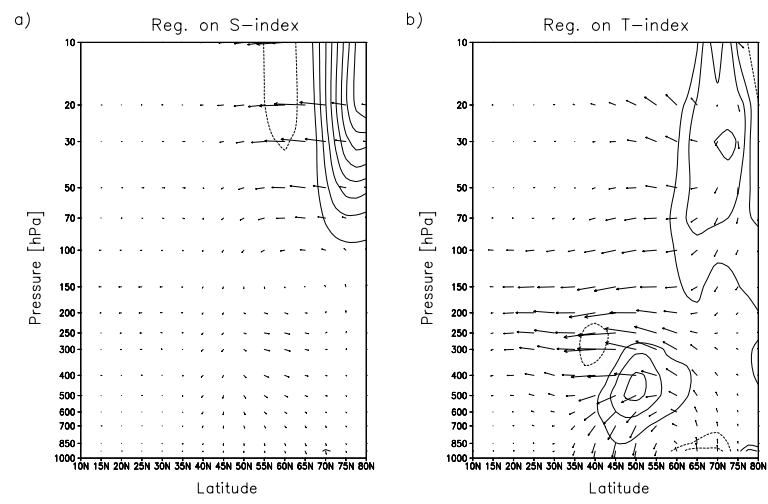

Figure 4. EP flux cross sections for the planetary waves of zonal wavenumbers 1 to 3 (vectors) and its divergence (contours) regressed on the normalized SIO index (a) and TIO index (b) based on winter data from 1959 to 1998. EP fluxes are scaled by the inverse of the air density. Unit for EP flux divergence is $\mathrm{ms}^{-1} \mathrm{day}^{-1}$. Contour interval is $1.0 \mathrm{in}$ (a) and 0.4 in (b). The zero contour line has been suppressed and the dashed lines indicate negative values. The indices and the data are detrended by subtraction of linear trends. 

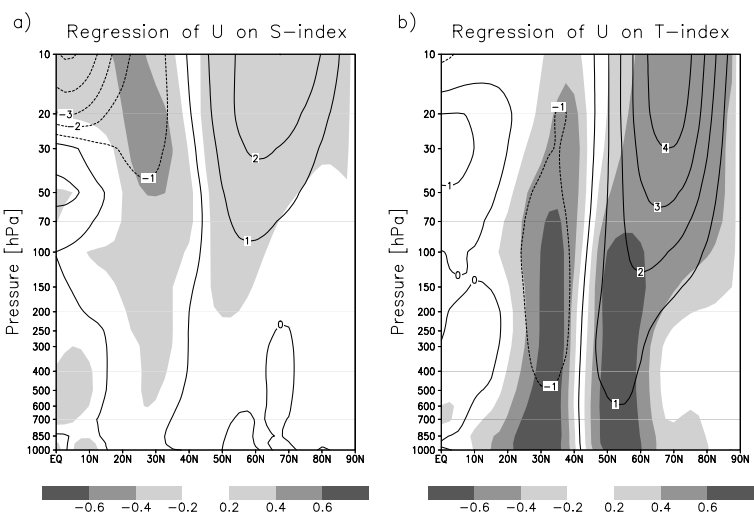

Figure 5. Regression (contours)/correlation (shading) pattern between $\overline{\mathrm{u}}$ anomalies and the normalized SIO index (a) and TIO index (b) based on winter data from 1959 to 1998. The indices and $\overline{\mathrm{u}}$ anomalies are detrended by subtraction of linear trends too. The regression values are in $\mathrm{ms}^{-1}$ and contour interval is 1.0 .

and enhanced westerlies around $55^{\circ} \mathrm{N}$ (Figure 5b) for positive TIO. This pattern strongly resembles the zonalmean geostrophic wind regressed on the standardized NAM index [see Figure $1 \mathrm{~b}$ of Thompson and Wallace, 2000]. Moreover, the correlations between the TIO index and $\overline{\mathrm{u}}$ anomalies are very large with maxima appearing at $\sim 35^{\circ} \mathrm{N}$ and $\sim 55^{\circ} \mathrm{N}$. Absolute correlation values exceed 0.6 at $\sim 35^{\circ} \mathrm{N}$ and $\sim 55^{\circ} \mathrm{N}$ from the surface through $70 \mathrm{hPa}$. Thus, one can conclude that the TIO is closely associated with the NAM.

[12] In fact, with the reconstructed monthly sea surface temperature (SST) data from NCAR's Data Support Section, we found that our SIO is significantly correlated with the SST in the tropics, mainly with SST anomalies which resemble patterns of El Niño/Southern Oscillation (ENSO) variability (Figure not shown). Detailed results of SST with the SIO and the TIO will be presented in another paper.

\section{Concluding Remarks}

[13] Observational analysis of 40 winter eddy forcings of $\overline{\mathrm{u}}$ due to stationary planetary waves for wavenumbers 1 through 3 indicates two oscillations, one in the stratosphere (SIO) and the other in the troposphere (TIO). The oscillations appear as dipole structures with divergence of EP flux in the north and convergence in the south, or vice versa. The temporal evolutions of the oscillations are different between in the stratosphere and in the troposphere, suggesting different dynamic mechanisms. The planetary waves tend to be bent equatorward in the troposphere and lower stratosphere during a positive TIO phase, and in the midand upper stratosphere during a positive SIO phase. The result also suggests that the upward propagation of planetary waves into the polar waveguide across the tropopause is closely linked to the meridional propagation of planetary waves in the troposphere. During the positive TIO phase planetary waves tend to be more effectively trapped in the troposphere than during the negative TIO phase.
[14] Linear regression analysis reveals that, for the TIO index, the structure of $\overline{\mathrm{u}}$ anomalies is an equivalent barotropic dipole extending from lower troposphere to upper stratosphere. The TIO is suggested to be closely related to the NAM. In addition, the teleconnectivity approach based on EP flux divergence brings our study closer to the origin of the variability process. And the correlation/regression analysis avoids the problems one faces when using EOFs, which not necessarily come up with physically based structures [Ambaum et al., 2001]. On the other hand, our results suggest that the behavior of mid-upper stratospheric atmosphere is associated with the ENSO.

[15] Acknowledgments. We would like to thank Prof. S. Miyahara, Dr. S. K. Dhaka and two reviewers for useful comments on this manuscript. W. Chen is supported by the National Key Developing Program for Basic Sciences under Grant G1998040900(I).

\section{References}

Ambaum, M. H. P., B. J. Hoskins, and D. B. Stephenson, Arctic Oscillation or North Atlantic Oscillation?, J. Climate, 14, 3495-3507, 2001.

Andrews, D. G., J. R. Holton, and C. B. Leovy, Middle atmosphere $d y$ namics, Academic Press, Orlando, pp. 489, 1987.

Chen, P., and W. A. Robinson, Propagation of planetary waves between the troposphere and stratosphere, J. Atmos. Sci., 49, 2533-2545, 1992.

Chen, W., and R.-H. Huang, The modulation of planetary wave propagation by the tropical QBO zonal winds and the associated effects in the residual meridional circulation, Contr. Atmos. Phys., 72, 187-204, 1999.

Davis, R. E., Predictability of sea surface temperature and sea level pressure anomalies over the North Pacific Ocean, J. Phys. Oceanogr., 6, 249-266, 1976.

DeWeaver, E., and S. Nigam, Do stationary waves drive the zonal-mean jet anomalies of the Northern Winter?, J. Climate, 13, 2160-2176, 2000.

Dunkerton, T. J., and M. P. Baldwin, Quasi-biennial modulation of planetary wave fluxes in the Northern Hemisphere winter, J. Atmos. Sci., 48, $1043-1061,1991$

Edmon, H. J., Jr., B. J. Hoskins, and M. E. McIntyre, Eliassen-Palm cross sections for the troposphere, J. Atmos. Sci., 37, 2600-2616, 1980.

Hartmann, D. L., J. M. Wallace, V. Limpasuvan, D. W. J. Thompson, and J. R. Holton, Can ozone depletion and global warming interact to produce rapid climate change?, Proc. Natl. Acad. Sci., 92, 1412-1417, 2000.

Kalnay, E., et al., The NCEP/NCAR 40-Year Reanalysis Project, Bull. Amer. Meteor. Soc., 77, 437-471, 1996.

Limpasuvan, V., and D. L. Hartmann, Eddies and the annular modes of climate variability, Geophys. Res. Lett., 26, 3133-3136, 1999.

Pawson, S., and M. Fiorino, A comparison of reanalyses in the tropical stratosphere. Part 3: inclusion of the pre-satellite data era, Clim. Dyn., 15, 241-250, 1999

Perlwitz, J., H.-F. Graf, and R. Voss, The leading variability mode of the coupled troposphere-stratosphere winter circulation in different climate regimes, J. Geophys. Res., 105, 6915-6926, 2000.

Shindell, D. T., D. Rind, and P. Lonergan, Increased polar stratospheric ozone losses and delayed eventual recovery due to increasing greenhouse gas concentrations, Nature, 392, 589-592, 1998.

Thompson, D. W. J., and J. M. Wallace, Annual modes in the extratropical circulation. Part I: Month-to-month variability, J. Climate, 13, 10001016, 2000.

Ting, M., M. P. Hoerling, T. Xu, and A. Kumar, Northern Hemisphere teleconnection patterns during extreme phases of the zonal-mean circulation, J. Climate, 9, 2615-2633, 1996.

Wallace, J. M., and D. S. Gutzler, Teleconnections in the geopotential height field during the northern hemisphere winter, Mon. Wea. Rev., $109,784-812,1981$.

W. Chen, LASG, Institute of Atmospheric Physics, Chinese Academy of Sciences, Beijing, China.

H.-F. Graf, Max-Planck-Institute for Meteorology, Hamburg, Germany. M. Takahashi, Center for Climate System Research, University of Tokyo, Tokyo, Japan. 